\title{
Effect of Dual Mesh Wrap on The Stability of Colonic Anastomosis
}

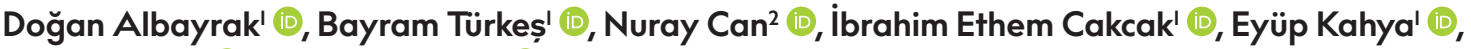 \\ Serhat Oğuz' (D, Zeki Hoșcoșkun' (1)
}

'Department of General Surgery, Trakya University School of Medicine, Edirne, Turkey

${ }^{2}$ Department of Medical Pathology, Trakya University School of Medicine, Edirne, Turkey

ORCID iDs of the authors: D.A. 0000-0002-I950-2444; B.T. 0000-0002-3949-II48; N.C. 0000-0003-2554-6432; i.E.C. 0000-000I-88855I4X; E.K. 0000-000I-5465-80I7; S.O. 0000-0003-I346-2194; Z.H. 0000-0002-4673-3483.

Cite this article as: Albayrak D, Türkeș B, Can N, Cakcak iE, Kahya E, Oğuz S, et al. Effect of Dual Mesh Wrap on The Stability of Colonic Anastomosis. Cyprus J Med Sci 202I; 6(I): 13-7.

\section{BACKGROUND/AIMS}

Colon anastomotic leakage is the cause of significant morbidity and mortality in surgery. Therefore, we aimed to demonstrate experimentally the effect of the conventional method of wrapping them through colo-colonic anastomosis performed by dual patch on anastomotic healing and security.

\section{MATERIAL and METHODS}

The study was conducted at the Experimental Animal Research Unit of the Medical Faculty of Trakya University, Edirne, Turkey. A total of 20 Wistar Albino adult rats were used. The rats were divided into 2 groups: 10 rats in the control group and 10 rats in the dual patch group. All rats underwent partial segmental colon resection, and colo-colonic anastomosis was performed in a single layer with $5 / 0$ polypropylene. For rats in the dual patch group, the anastomosis was wrapped up with a l-cm-wide dual patch. In the control group, there was no operation on the anastomosis. At 7 days after the procedure, the degree of peritoneal adhesion model previously prepared according to Evans devices laparotomy was used to observe all the rats and colon burst pressure. Both histopathological examination and the examination of the perianastomotic area were performed.

\section{RESULTS}

In the rats that were treated with dual mesh, there was a statistically significant increase in anastomotic line burst pressure ( $P<.05)$, a statistically significant increase in collagen amount $(P<.05)$, and a statistically significant decrease in abdominal adhesions $(P<.05)$.

\section{CONCLUSION}

As a result, the colo-colonic anastomosis of winding dual patch, without causing intra-abdominal adhesions, improves security by increasing the anastomosis bursting pressure.

Keywords: Colorectal surgery, mesh, anastomotic leakage

\section{INTRODUCTION}

One of the most serious complications after colorectal surgery is anastomotic leakage, which is associated with high morbidity and mortality. In 1826, Denans (I) designed a device that performed colonic anastomosis without suture. In I892, Murphy developed another device composed of 2 metallic rings that could connect the ends of the intestine with a button. Since then, many techniques for colonic anastomoses have been developed that aim to prevent or reduce the complications associated with anastomoses. More than half of postoperative deaths are caused by sepsis associated with anastomotic leakage (2). The frequency of anastomotic leakage after colonic resection was reported to be between $0.5 \%$ and $30 \%(\mathrm{I}, 2)$.

Various techniques have been proposed for anastomosis, and treatment modalities have been suggested to prevent anastomotic leakage. One treatment modality is wrapping the intestinal anastomosis with various prosthetic materials, such as polypropylene mesh (2). However, polypropylene mesh can cause intra-abdominal adhesions (3).

In this study, we evaluated the effect of wrapping colonic anastomosis in a dual mesh on anastomotic stability. The dual mesh was not expected to cause intra-abdominal adhesions. 


\section{MATERIAL and METHODS}

This study was performed at the Experimental Animals Research Unit, School of Medicine, University of Trakya Ethical approval was obtained from the local ethics committee of the University of Trakya Faculty of Medicine. A total of 20 adult Wistar Albino rats aged 6 to 8 months were used. The mean weight of the rats was $210 \mathrm{~g}(180-230 \mathrm{~g})$.

\section{Anesthesia and Surgical Procedures}

Rats were maintained in 12 -hour dark and light conditions, with a room temperature of $22^{\circ} \mathrm{C} \pm 1^{\circ} \mathrm{C}$ and humidity of $50 \%$ to $60 \%$. Rats were fed with standard pellet feed and had access to city potable water until the day of the experiment. Rats were fasted for 12 hours before the experiment but were allowed to drink water until 30 minutes before the experiment. No colon cleansing was performed. Preprocedure anesthesia was provided using 5 to $10 \mathrm{mg} / \mathrm{kg}$ xylazine hydrochloride (Rompun, Bayer, Istanbul, Turkey) administered intramuscularly and ketamine hydrochloride (Ketalar, Pfizer, Istanbul, Turkey). Rats lying in the supine position were fixed to operating beds with adhesive bands, the abdominal hair was clipped, and the skin was cleansed using

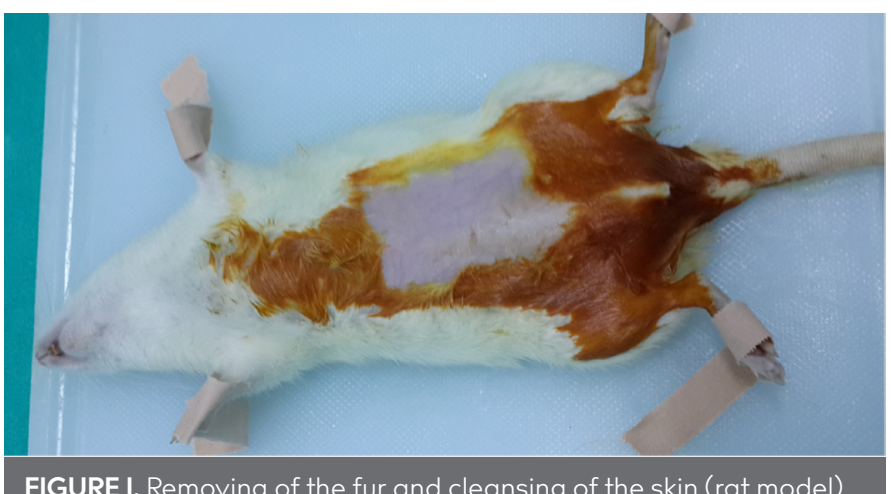

FIGURE I. Removing of the fur and cleansing of the skin (rat model)

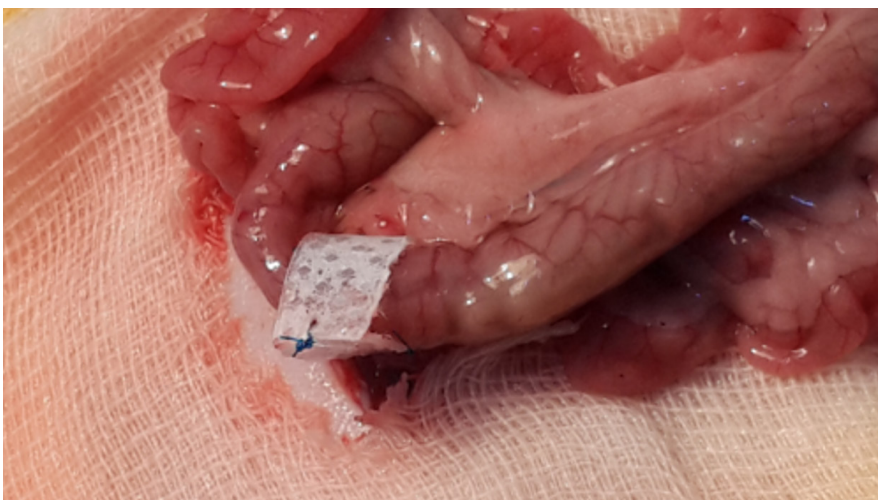

FIGURE 2. Attaching the dual mesh to the anastomotic suture line

\section{Main Points:}

- Winding a dual mesh around colocolic anosthomoses in rats provides better burst pressures.

- Winding a dual mesh around colocolic anosthomoses in rats provides increased collagen amount in healing anosthomosis

- Winding a dual mesh around colocolic anosthomoses in rats significantly decreases the amount of abdominal adhesions. povidone-iodine (Figure I). A midline incision was made in the lower abdominal region using a number 15 blade. A colon segment with a length of I or $2 \mathrm{~cm}$ distal to the cecum was resected. Then, a single-layer colonic anastomosis was performed using a 5/0 polypropylene suture. Rats in group I $(n=10)$ underwent no other procedure, and the abdominal layers and skin were closed separately using 3/0 polypropylene sutures. In group II rats, the colonic anastomosis was wrapped with a dual mesh (Polymesh, Betatech Medical, Istanbul, Turkey) that was I cm in width and had a length equal to the circumference of the anastomosis. The mesh was wrapped so that the polypropylene layer was in contact with the colonic serosa (Figure 2). The abdominal layers and skin were then closed separately using a 3/0 polypropylene suture.

\section{Evaluation}

Rats were allowed to feed normally 12 hours after the surgery, and water intake was not limited. At 7 days after the surgery, all rats were anesthetized with ketamine and xylazine and killed by exsanguination. After death was confirmed, a large incision was applied to the anterior abdominal wall to expose all peritoneal cavities. The intra-abdominal adhesion was graded according to the Evans model (Table I).

The anastomotic line was resected $2 \mathrm{~cm}$ from the proximal and distal parts to measure the bursting pressure of the anastomosis. The distal end of the intestinal segment was tied with a $2 / 0$ silk suture. An I8F catheter was introduced into the proximal end, and the other end of the catheter was connected to a transducer and air pump. This system allowed us to measure the intraluminal pressure of the resected intestinal segment ( $\mathrm{mm} \mathrm{Hg}$ ) (Figure 3 ). The intestinal segment was soaked in a water-filled container, and air was pumped into the lumen in a controlled manner. The point of the first air leak from the colon wall was recorded as the anastomotic bursting pressure.

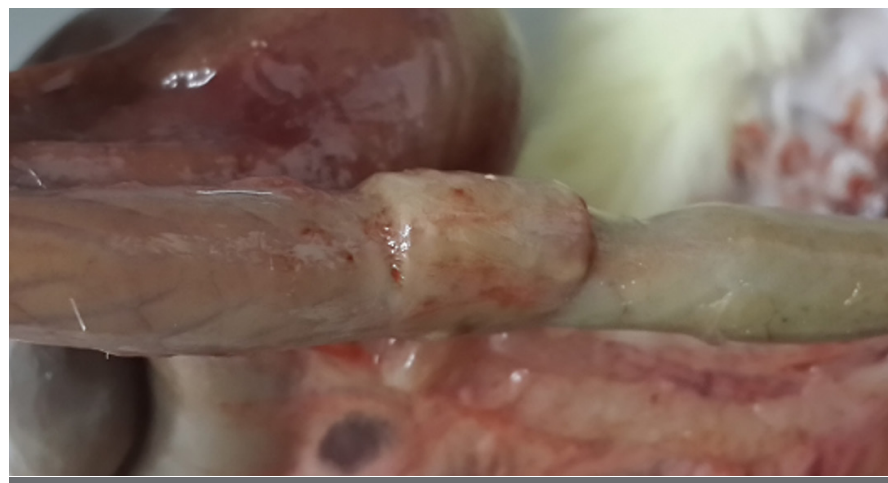

FIGURE 3. Macroscopic view of the anastomosis at the end of the experiment

TABLE I. Evans Model (intra-abdominal adhesions)

$\begin{array}{ll}\text { Adhesion Stage } & \text { Definition } \\ 0 & \text { No adhesion } \\ 1 & \text { Spontaneously separating adhesions } \\ 2 & \text { Adhesions separated by traction } \\ 3 & \text { Adhesions separated by dissection }\end{array}$




\section{Histopathological Examination}

Histopathological evaluation was performed by a single pathologist at the Department of Medical Pathology, University of Trakya. The anastomotic line was cut together with I cm of surrounding tissue from each side and fixed in 10\% formaldehyde. Fixed tissues were embedded in paraffin blocks and sectioned. Thin sections were stained with hematoxylin and eosin dye and examined using light microscopy. Images were captured by a computer. Histopathological staging of the anastomotic line was performed according to the Ehrlich-Hunt model. The following parameters were evaluated: inflammatory cell infiltration, neovascularization, fibroblast activity, and the amount of collagen (Table 2).

\section{Statistical Analysis}

Statistical evaluation was performed using the STATISTICA AXA 7.I statistical program. Normal distribution of measurable variables was tested using the Kolmogorov-Smirnov test. Between-groups analysis was performed using variance analysis

\begin{tabular}{ll} 
TABLE 2. Ehrlich-Hunt model & $\begin{array}{l}\text { Inflammatory cell/fibroblastic activity/neovascularization/ } \\
\text { amount of collagen }\end{array}$ \\
\hline 1 & Low density and separated \\
2 & Low density and in all places \\
3 & High density but separated \\
4 & High density and in all places
\end{tabular}

TABLE 3. Distribution of adhesion grades according to Evans model

\begin{tabular}{lcc}
$\begin{array}{l}\text { Adhesion scores according } \\
\text { to Evans model }\end{array}$ & $\begin{array}{c}\text { Control group } \\
(\mathbf{n}=10)\end{array}$ & $\begin{array}{c}\text { Dual mesh } \\
\text { group }(\mathbf{n}=10)\end{array}$ \\
\hline Grade 0 & 0 & $10 \%$ \\
No adhesion & 0 & $(n=1)$ \\
Grade I & & $40 \%$ \\
Spontaneously separating adhesions & $20 \%$ & $(n=4)$ \\
Grade 2 & $(n=2)$ & $(n=5)$ \\
Adhesions separated by traction & $80 \%$ & \\
Grade 3 & $(n=8)$ & 0 \\
Adhesions separated by dissection & &
\end{tabular}

TABLE 4. Adhesion score average according to Evans model

\begin{tabular}{lccc}
$\begin{array}{l}\text { Adhesion scores } \\
\text { according to } \\
\text { Evans Model }\end{array}$ & $\begin{array}{c}\text { Control group } \\
(\boldsymbol{n}=10)\end{array}$ & $\begin{array}{c}\text { Dual mesh group } \\
(\boldsymbol{n}=10)\end{array}$ & $\mathbf{p}$ * \\
\hline Mean \pm SD & $2.8 \pm 0.42$ & $1.4 \pm 0.69$ & \\
Median (Min-Max) & $3(2-3)$ & $1.5(0-2)$ & $p<0.001$
\end{tabular}

Mann-Whitney U test; * $p<0.05$ statistically significant; SD: Standard deviation; Min: Minimum; Max: Maximum

TABLE 5. Bursting pressures

\begin{tabular}{|c|c|c|c|}
\hline $\begin{array}{l}\text { Bursting pressure } \\
(\mathrm{mmHg})\end{array}$ & $\begin{array}{c}\text { Control } \\
\text { group }(n=10)\end{array}$ & $\begin{array}{c}\text { Dual mesh } \\
\text { group }(n=10)\end{array}$ & $\mathrm{p}^{*}$ \\
\hline Mean \pm Standard deviation & $140 \pm 13.3$ & $205 \pm 22.7$ & \\
\hline Median (Min-Max) & $140(120-160)$ & $200(180-250)$ & $p<0.001$ \\
\hline
\end{tabular}

and post hoc Tamhane and Bonferroni tests (for variables with normal distribution) and with Kruskal-Wallis variance analysis and Mann-Whitney Utests (for variables without normal distribution). Median (minimum-maximum) values and mean \pm standard deviation values were used for descriptive statistics. A $P$ value $<.05$ was considered statistically significant.

\section{RESULTS}

No mortality occurred because of anesthesia or the surgical procedure. No macroscopic anastomotic leakage was detected in the killed rats.

\section{Evaluation of Intra-Abdominal Adhesions}

Adhesions were staged as follows: stage 0, no adhesions; stage I, adhesions released without intervention; stage 2, adhesions released by pulling; and stage 3 , adhesions released by dissection. Stage 3 adhesions were observed in 8 rats in group l, and stage 2 adhesions were observed in 2 rats in group I. Five rats that received the dual mesh (group II) had stage 2 adhesions, and 4 rats had stage I adhesions. One rat had no adhesions (stage 0) (Table 3).

The distribution of adhesion scores was evaluated using the Evans model. The mean adhesion scores were as follows: $2.8 \pm 0.42$ for the control group (group I) and I.4 \pm 0.69 for the dual mesh group (group II). The mean adhesion score in the dual mesh group (group II) was significantly lower than that in the control group (group I) $(P<.00 I)$ (Table 4$)$.

\section{Measurement of Bursting Pressure}

The mean bursting pressure was $140 \pm 13.3 \mathrm{~mm} \mathrm{Hg}$ in the control group and $205 \pm 22.7 \mathrm{~mm} \mathrm{Hg}$ in the dual mesh group. No bursting occurred in rats fitted with the dual mesh in the anastomotic line. However, bursting did occur in other colonic tissues. The mean bursting strength in the dual mesh group was significantly higher than that in the control group $(P<.001)$ (Table 5).

\section{Histopathological Evaluation}

The anastomotic lines were histopathologically staged according to the Ehrlich-Hunt model. The scores for inflammatory cell infiltration, fibroblast activity, neovascularization, and collagen are shown in Table 6.

The mean inflammatory cell score was $3.9 \pm 0.31$ in the control (group I) and $2.7 \pm 0.82$ in the dual mesh group (group II). The mean inflammatory cell score was significantly lower in the dual mesh group (group II) than in the control group ( $P=.002)$.

The mean fibroblast activity score was $3.9 \pm 0.31$ in the control group (group I) and $2.7 \pm 0.94$ in the dual mesh group (group II). The mean fibroblast activity score was significantly lower in the dual mesh group (group II) than in the control group ( $P=.004)$.

The mean neovascularization score was $3.9 \pm 0.31$ in the control group (group I) and $2.7 \pm 0.82$ in the dual mesh group (group II). The mean neovascularization score was significantly lower in the dual mesh group (group II) than in the control group $(P=.002)$.

The mean amount of collagen was $2.3 \pm 0.48$ in the control group (group I) and $3.2 \pm 0.63$ in the dual mesh group (group II). The mean fibroblast activity score was significantly higher in the dual mesh group (group II) than in the control group $(P=.005)$. 


\begin{tabular}{|c|c|c|c|}
\hline \multirow[b]{2}{*}{$\begin{array}{l}\text { Histopathologic } \\
\text { staging }\end{array}$} & Control group & Dual mesh group & \multirow[b]{2}{*}{$\mathrm{p}^{*}$} \\
\hline & $\begin{array}{l}\text { Mean } \pm \text { SD } \\
\text { Median } \\
\text { (Min-Max) }\end{array}$ & $\begin{array}{l}\text { Mean } \pm \text { SD } \\
\text { Median } \\
\text { (Min-Max) }\end{array}$ & \\
\hline Inflammatory cell & $\begin{array}{c}3.9 \pm 0.31 \\
4(3-4)\end{array}$ & $\begin{array}{l}2.7 \pm 0.82 \\
2.5(2-4)\end{array}$ & $p=0.002$ \\
\hline Fibroblast activity & $\begin{array}{c}3.9 \pm 0.31 \\
4(3-4)\end{array}$ & $\begin{array}{l}2.7 \pm 0.94 \\
2(2-4)\end{array}$ & $p=0.004$ \\
\hline Neovascularization & $\begin{array}{c}3.9 \pm 0.31 \\
4(3-4)\end{array}$ & $\begin{array}{l}2.7 \pm 0.82 \\
2.5(2-4)\end{array}$ & $p=0.002$ \\
\hline Amount of collagen & $\begin{array}{l}2.3 \pm 0.48 \\
2(2-3)\end{array}$ & $\begin{array}{c}3.2 \pm 0.63 \\
3(2-4)\end{array}$ & $p=0.005$ \\
\hline Total & $\begin{array}{l}14 \pm 0.66 \\
14(13-15)\end{array}$ & $\begin{array}{l}11.3 \pm 2.05 \\
10(9-15)\end{array}$ & $p=0.006$ \\
\hline $\begin{array}{l}\text { Mann-Whitney U te } \\
\text { deviation; Min: Mini }\end{array}$ & $\begin{array}{l}0.05 \text { statis } \\
\text { Max: Maxim }\end{array}$ & significant; SD & andard \\
\hline
\end{tabular}

The total mean histological scores were significantly lower in the dual mesh group than in the control group $(P=.006)$.

\section{DISCUSSION}

Colonic anastomoses are frequently used during abdominal surgery (I). Manual single-layered colonic anastomoses are performed to prevent anastomotic stenosis $(1,3,4)$. An increasing number of anastomoses have been performed after surgeries to remove colorectal tumors, which is proportional to the increasing age of the population (5). The most appropriate technique for reducing the mortality and morbidity rates associated with anastomosis has still not been defined. Many experimental studies have been performed to investigate ways to support the anastomosis with prosthetic materials (6). In this study, we examined whether a dual mesh could support the colonic anastomosis. We assumed that this would cause no intra-abdominal adhesions. Dual mesh as a means of supporting anastomosis has not been investigated previously.

Any intra-abdominal intervention will inevitably result in adhesions (7), including the intraperitoneal use of a prosthetic material (such as polypropylene mesh) (8). Adhesions are the principal reason for postoperative mechanical obstruction of the intestine; therefore, they must be avoided if possible. We hypothesized that a dual mesh would provide mechanical support to the anastomosis without increasing the formation of adhesions. We found that adhesion formation was significantly lower in rats fitted with dual mesh than in control rats. This indicates that a dual mesh prevents perianastomotic and intra-abdominal adhesions, which will decrease long-term intestinal obstruction.

Wound healing can be monitored by tissue inflammation, neovascularization, fibroblast activity, and collagen levels (3). We evaluated these parameters in the anastomotic line to measure wound healing $(2,3)$. Healing after colonic anastomosis is directly proportional to the amount of collagen in the anastomotic line (9). Prosthetic material such as polypropylene is known to stimulate collagen production in the tissues they come into contact with (10). Therefore, a dual mesh with propylene in contact with the intestinal wall (as used in this study) should promote collagen synthesis and hence, the healing and stability of the colonic anastomosis. In agreement with previous findings, the collagen levels were higher in the anastomotic line of rats fitted with the dual mesh. However, other parameters of wound healing, such as inflammatory cell infiltration, neovascularization, and fibroblast activity, were lower in rats fitted with the dual mesh. When all parameters were analyzed together, tissue healing was found to be significantly better in rats without the dual mesh. We believe that this can be attributed to the early termination of the experiment on the seventh postoperative day. If the dual mesh were in contact with the anastomotic line for a longer time, then the other wound healing parameters would likely change in favor of the dual mesh group, as was the case for the collagen levels.

An anastomosis wrapped with a material that is relatively less elastic, such as dual mesh, is less likely to shrink and result in stenosis. No mechanical intestinal obstructions were observed in this study. However, the 7-day study period was too short to draw firm conclusions. In addition, we used rats in our study; therefore, care should be taken when extrapolating these findings to humans. Further investigations are required to determine the effectiveness of this method in humans.

We did not observe any bursting of the anastomotic line in rats fitted with the dual mesh. This shows that the dual mesh provided important mechanical support to the anastomosis. The anastomotic bursting pressure is a marker of the anastomotic line resistance to intraluminal pressure and is a reliable method for evaluating anastomotic healing. Anastomotic bursting pressure is directly proportional to the mass of collagen in the tissue, which forms cross links to stabilize the tissue $(9,10)$. The dual mesh used in this study provided a barrier in regions that induce anastomotic leakage (particularly in the suture holes), thereby increasing anastomotic safety.

We have shown that the use of a dual mesh reduces anastomotic bursting and intra-abdominal adhesions during the early postoperative period. Long-term follow-up of rats fitted with the dual mesh is required. In conclusion, wrapping the colonic anastomotic line with a dual mesh increases anastomotic stability by increasing collagen levels and anastomotic bursting pressure without causing intra-abdominal adhesions.

Ethics Committee Approval: Ethics committee approval was received for this study from the ethics committee of Trakya University (Approval date: 29.09.2014, No: 2014.09.02).

Informed Consent: N/A

Peer-review: Externally peer-reviewed.

Author contributions: Concept - D.A., B.T., Z.H.; Design - D.A., B.T.; Supervision - Z.H., D.A.; Resource - D.A.; Materials - I.E.C., E.K.; Data Collection and/or Processing - B.T., N.C.; Analysis and/or Interpretation - D.A., N.C.; Literature Search - B.T.; Writing - D.A., B.T., S.O.; Critical Reviews - Z.H., D.A., S.O.

Conflict of Interest: Authors have no conflicts of interest to declare.

Financial Disclosure: The authors declared that this study has received no financial support. 


\section{REFERENCES}

I. Jex RK, Van Heerden JA, Wolff BG, Ready RL, Ready RL, Ilstrup DM. Gastrointestinal anastomoses. Ann Surg 1987; 206(2): 138-4l. [Crossref]

2. Aysan E, Dincel O, Bektas H, Alkan M. Polypropylene mesh covered colonic anastomosis. Results of a new anastomosis technique. Int $J$ Surg 2008; 6(3): 224-9. [Crossref]

3. Cipe G, Malya FU, Hasbahceci M, Atukeren P, Buyukpinarbasili $\mathrm{N}$, Karatepe $\mathrm{O}$, et al. A novel sutureless colonic anastomosis with self-gripping mesh: an experimental model. Int J Clin Exp Med 2014; 7(5): 1255-61.

4. Cahill CJ, Betzler M, Gruwez JA, Jeekel J, Patel J-C, Zederfeldt B. Sutureless large bowel anastomosis: European experience with the biofragmentable anastomosis ring. Br J Surg 1989; 76(4): 344-7. [Crossref]
5. Kim JH. Chemotherapy for colorectal cancer in the elderly. World J Gastroenterol 2015; 21(17): 5158-66. [Crossref]

6. Aysan E, Bektas H, Ersoz F, Sari S, Kaygusuz A. A novel colonic anastomosis technique involving fixed polyglycolic acid mesh. Int J Clin Exp Med 20I0; 3(4): 34l-6.

7. Mais $\vee$. Peritoneal adhesions after laparoscopic gastrointestinal surgery. World J Gastroenterol 2014; 20(17): 4917-25. [Crossref]

8. Baykal A, Yorganci K, Sokmensuer C, Hamaloglu E, Renda N, Sayek I. An experimental study of the adhesive potential of different meshes. Eur J Surg 2000; 166(6): 490-4. [Crossref]

9. Jönsson $\mathrm{K}$, Jiborn $\mathrm{H}$, Zederfeldt B. Mechanical and biochemical alterations in the intestinal wall adjacent to an anastomosis. Am J Surg 1986; I5I(3): 387-90. [Crossref]

10. Law NW, Ellis $\mathrm{H}$. Adhesion formation and peritoneal healing on prosthetic materials. Clinical Mater 1988; 3: 95-I0I. [Crossref] 